Editorial

\title{
Social Inclusion and Exclusion for First Nations LGBTIQ+ People in Australia
}

\author{
Karen Soldatic ${ }^{1, *}$, Corrinne Sullivan ${ }^{2}$, Linda Briskman ${ }^{2}$, John Leha ${ }^{3}$, William Trewlynn ${ }^{3}$ and Kim Spurway ${ }^{1}$ \\ ${ }^{1}$ Institute for Culture and Society, Western Sydney University, Penrith, NSW 2751, Australia; \\ E-Mails: k.soldatic@westernsydney.edu.au (Ka.S.), k.spurway@westernsydney.edu.au (Ki.S.) \\ 2 School of Social Sciences, Western Sydney University, Penrith, NSW 2751, Australia; \\ E-Mails: corrinne.sullivan@westernsydney.edu.au (C.S.), I.briskman@westernsydney.edu.au (L.B.) \\ 3 BlaQ Aboriginal Corporation, Sydney, NSW 2060, Australia; E-Mail: william@blaq.org.au (W.T.) \\ * Corresponding author
}

Submitted: 19 March 2021 | Published: 15 April 2021

\begin{abstract}
This thematic issue of Social Inclusion highlights the connections between First Nations LGBTIQ+ people's intersecting identities and inclusionary and exclusionary process in settler-colonial Australia. In this editorial, we briefly introduce key concepts and summarise the different contributions in the issue, providing some general conclusions and guidance on a possible future research agenda.
\end{abstract}

\section{Keywords}

Aboriginal; First Nations; Indigenous; LGBTIQ+; social inclusion; social exclusion; Torres Strait Islander; wellbeing

\section{Issue}

This editorial is part of the issue "Young, Indigenous, LGBTIQ+: Understanding and Promoting Social and Emotional Wellbeing" edited by Karen Soldatic (Western Sydney University, Australia), Linda Briskman (Western Sydney University, Australia), William Trewlynn (BlaQ Aboriginal Corporation, Australia), John Leha (BlaQ Aboriginal Corporation, Australia), Corrinne Sullivan (Western Sydney University, Australia) and Kim Spurway (Western Sydney University, Australia).

(C) 2021 by the authors; licensee Cogitatio (Lisbon, Portugal). This editorial is licensed under a Creative Commons Attribution 4.0 International License (CC BY).

\section{Introduction}

In this thematic issue of Social Inclusion, we interrogate some of the contested, complex and intersecting meanings around the social inclusion and exclusion of Aboriginal and/or Torres Strait Islander LGBTIQ+ people in modern colonial settler Australia. The thematic issue originally aimed to include studies of First Nations LGBTIQ+ people worldwide. However, the current issue only focuses on First Nations LGBTIQ+ people living in Australia. This is in part due to the impact of Covid-19 on authors from North America, for example, who were forced to withdraw their articles due to the impact of Covid-19 on their families and communities. We also acknowledge that this thematic issue reflects the fact that the journal is published in English and this may have excluded research from non-English speaking countries with significant First Nations populations.
The publication of this thematic issue is highly significant for several reasons. There has been very little published on the lived experiences, needs and aspirations of First Nations LGBTIQ+ people. Globally, what research exists in English has historically focused on North American First Nations populations (see Soldatic, Briskman, Trewlynn, Leha, \& Spurway, 2021a). This issue is unique in that all the articles investigate issues around Aboriginal and/or Torres Strait Islander LGBTIQ+ people living in Australia. The articles combined, therefore, represent a unique collection of First Nations LGBTIQ+ people's experiences in Australia. There has been minimal research into pre-invasion and contemporary First Nations cultures and gender and sexuality diversity in Australia (Bayliss, 2015). The US and Canada both started to gather information on this topic much earlier and have rich, extensive bodies of research. In New Zealand, there also has been some limited research in the early 
2000s through initiatives such as the Māori Sexuality Project at Auckland University (Aspin \& Hutchings, 2007). As such, this thematic issue gives a unique insight into the Australian experience, demonstrating the diversity of Aboriginal and/or Torres Strait Islander LGBTIQ+ people's identity and cultural resistance to heteropatriarchal and heteronormative colonial settler value systems. We add significant new insights and findings to the existing body of literature in English from the US, Canada and New Zealand.

The editors believe that research such as this should be designed and led by First Nations LGBTIQ+ people both as researchers and as participants. One of the few published reports on First Nations LGBTIQ+ people in Australia rightly states: "Sexuality and gender diverse populations are an invisible minority in a national minority group" (Dudgeon, Bonson, Cox, Georgatos, \& Rouhani, 2015, p. 3). In keeping with some of the of the principles proposed by authors such as Tuhiwai Smith (2013) and Sullivan (2020) in researching with Indigenous communities, the editors of this thematic issue prioritised articles authored by First Nations researchers, preferably First Nations LGBTIQ+ researchers. As a consequence, one of the most important features of this issue is that four out of the five articles are authored or co-authored by First Nations LGBTIQ+ people. Out of the 11 authors in this issue, six openly identify as First Nations LGBTIQ+ people, and four of these are academics at an early stage of their career.

Bronwyn Carlson (2016, p. 13) observes that "expressions of Aboriginal identity are multifarious" and this diversity is reflected in the variety of terms used by authors in this issue to identify the variety of people included in their studies. Henningham (2021), in interrogating her own lived experiences through autoethnography, uses terms such as 'Blak,' 'Bi+,' 'LGBTIQ+' and 'Queer.' Phelan and Oxley (2021) look at the needs of Aboriginal LGBTIQ(SB)+ in youth detention in Victoria, adding uniquely Aboriginal and/or Torres Strait Islander identities, 'sistergirls' and 'brotherboys,' to nuance the more generic acronym. In their study on Aboriginal and/or Torres Strait Islander LGBTIQ+SB's inclusion in education, Rhodes and Byrne (2021) also add sistergirls and brotherboys to the acronym. Soldatic et al. (2021b) look at the impact of inclusionary and exclusionary practices and institutions on First Nations LGBTIQ+ young people's wellbeing. Sullivan (2021), in turn, investigates the lived experiences of an Indigenous gay cis-male sex worker. Though we recognise that this selection of articles does not represent the diversity and extent of First Nations LGBTIQ+ experiences and identities in Australia, it nonetheless gives a small glimpse at the breadth of First Nations sexuality and gender diversity identities in the country.

\section{Overview of Contributions}

The overall aim of this thematic issue is to interrogate the contested and complex meanings for Aboriginal and/or Torres Strait Islander LGBTIQ+ people living in the modern settler colonial state of Australia. Authors have all taken very different paths towards investigating the impact of exclusionary and inclusionary practices, processes and structures on First Nations LGBTIQ+ people. Henningham (2021) uses autoethnography to reframe and explore the challenges of living as an Indigenous $\mathrm{Bi}+$ woman in Australia. She uses Borderland Theory to help her analyse her experiences of living on the border spaces of different communities exploring her intersecting identities being Blak and $\mathrm{Bi}+$. She concludes that this act of self-interrogation itself can be self-isolating and has the realisation that she is viewed as being too disconnected from Indigenous communities to be considered 'Blak' and not queer enough to be accepted by non-Indigenous LGBTIQ+ communities. As a result, her exclusion from multiple communities has impacted on her "performative self-expression of sexual identity, self-sabotage, institutionalized racism and shadeism, and community acceptance, particularly for $\mathrm{Bi}+$ sexual identities" (Henningham, 2021, p. 7). Despite the relative privilege of 'passing' in both communities, Henningham also identifies internalised phobias that contribute towards poor wellbeing based on fear of exclusion and rejection. Henningham's lived experiences demonstrate the importance of interconnectedness of all aspects of her wellbeing from the individual to the collective level (community, culture, country). Future research, she argues, needs to broaden its scope to include understandings of the complexities of these intersecting, plural identities. Henningham further identifies issues for future research such as suicide and intergenerational trauma and calls for more work on mental health to reduce suicide rates and improve wellbeing for Indigenous LGBTIQ+/Bi+ youth.

Phelan and Oxley (2021) focus on Aboriginal LGBTIQ(SB)+ youth in detention in the state of Victoria in the southeast of Australia. Significant harm is being done to Aboriginal LGBTIQ(SB)+ youth by the professional disciplines involved in their incarceration processes. Young people are being problematised and pathologised as social justification for violent, exclusionary and discriminatory practices within the criminal justice system. The authors find that there has been some progress to date, however, these problematic practices continue to exist either out of conscious or unconscious racism and heterosexism. These racist, heterosexist practices impact on any opportunity to improve service delivery, treatment, recovery and rehabilitation programmes. The authors call for mental health and therapeutic programmes in the criminal justice system to take a strength-based approach that promotes and prioritises the unique cultural needs of Aboriginal LGBTIQ+ youth. The current system is failing because it is based on Western racist, heterosexist paradigms that are culturally biased and discriminatory. To develop better youth justice frameworks, criminal justice programmes need to be centred on the voices and experiences of Aboriginal LGBTIQ+ youth. In order to do this, the sys- 
tem needs to better engage with Aboriginal and LGBTIQ+ community-controlled organisations that can better represent the needs and aspirations of Aboriginal LGBTIQ+ young people.

Rhodes and Byrne argue for the need to embed Aboriginal and Torres Strait Islander LGBTIQ+SB issues into Australian primary school educational curricula. Although a contested concept, the authors use Intersectionality Theory to highlight "the multitude of racial, social, political, and economic factors which can serve to marginalise people" (Rhodes \& Byrne, 2021, p. 32). The authors demonstrate the need for curricula that present different ways of being that are based on culturally appropriate and affirmative approaches. Starting the process with teacher training is important, they argue, since in order to effectively educate students, teachers need to understand the context of their students' lives. This means that teachers need to be inclusive of the needs of all students and understand the intersecting, multiple identities that can lead to complex disadvantages and a lack of progress in educational terms. To achieve this goal, Rhodes and Byrne argue, teachers need to be affirmed and supported through government policy and regulation. Schools and state Education Departments also need to modify policies to create affirming and safe environments for Aboriginal LGBTIQ+. Teachers need to be proactive, engaging with the key concerns of their students and undertaking their own research. The authors conclude, however, that inclusive and critical Initial Teacher Education programs play a pivotal role in equipping teachers with the requisite knowledge and understanding of intersectional disadvantage and educational needs of Aboriginal LGBTIQ+ people.

Soldatic et al. (2021b) investigate the social, cultural and emotional wellbeing of queer identifying urban Aboriginal and/or Torres Strait Islander youth living on the east coast of Australia. The authors use Indigenous definitions of social inclusion and exclusion, predominantly basing their approach on Indigenous understandings of social inclusion/exclusion that include community, culture and country. Their research demonstrates the importance of acceptance and support from Aboriginal and/or Torres Strait Islander families and communities for social inclusion and exclusion. In particular, participants highlighted the importance of the role of mothers in feeling accepted, safe and comfortable, enabling participants to overcome challenges to their wellbeing. Other relatives such as sisters and brothers as well as friendship networks were also important but not highlighted to the same degree as mothers. Despite some challenges encountered with extended families still living on country, many participants stressed the importance of an ongoing connection to country and extended family and kinship groups (grandmothers, grandfathers, aunts, uncles, cousins, etc.). For some First Nations LGBTIQ+ youth, non-Indigenous LGBTIQ+ communities could act as a second family that provided protection and support for their wellbeing. Some young people expressed concern, however, about the levels of racism within these communities, making them feel excluded and marginalised. Despite this, participants demonstrated how they effectively navigated and resisted neo-colonial attempts to erase identity, culture and wellbeing with support from mothers, families and communities.

Drawing on Indigenous Standpoint and Wellbeing Theory as an analytic tool, Sullivan (2021) explores the lived experiences of a young, gay, cis-male sex worker in Sydney, Australia. She finds that although Jack is, in many ways, socially and financially well, he is also excluded by the lack of social/cultural validation and belonging. Sullivan draws out Jack's social exclusion; he is culturally marginalised, has restricted mobility and social inequalities. His status as an Aboriginal man is the foundation for much of Jack's social inequalities caused by racism in the non-Indigenous queer communities. Despite this, urban Indigenous queer people like Jack are creating their own spaces of inclusion, creating new communities separate from urban queer and Aboriginal spaces that allow them to thrive. Jack's "connection to other queer, and sex worker, Indigenous peoples has given him a space in which to connect to his culture by forming his own communities of practices, values, and knowledges" (Sullivan, 2021, p. 57). Jack's exclusion from his Aboriginal community makes Sullivan question the idea of an Indigenous whole of community concept and its importance to individual wellbeing. She argues that there is also the need for individual empowerment as an essential element for any community wellbeing and structural change in community. Inclusion, belonging and connecting is very context based, Sullivan concludes, and is closely linked to how various social and cultural networks affect individuals with both negative and positive implications for wellbeing. She also finds that the experiences of sex work are much more nuanced than current literature suggests, as it ignores Aboriginal sex worker experiences and overly focuses on negativity and anxieties around cultural taboos. Jack's lived experiences challenges these assumptions, especially as he does not fit into the dominant cultural heteronormativity of many Aboriginal communities. Sullivan (2021, p. 58) calls on researchers to acknowledge the complex layers of identity for people like Jack and to speak back to "coloniocentric narratives."

O'Sullivan's commentary demonstrates, through their own research agenda on creative representation and personal reflection, the need to shine light on the diversity and multiplicity of $L G B T I Q+$ Indigenous peoples. O'Sullivan (2021) brings to bare the limited presence of Indigenous and/or queer peoples within creative spaces such as film, television and beyond, and what effect queer visibility has on the social and emotional wellbeing of Indigenous LGBTIQ+ people. This limited presence is a reflection of the absence of visibility and a pertinent reminder that for Indigenous queer people "you can't be what you can't see" (Young, 2018, as cited in O'Sullivan, 2021, p. 63). O'Sullivan therefore insists that visibility be narrated by Indigenous LGBTIQ+ peoples 
amidst the construction of their multiplicities, complexities and diversities, and furthermore that space remains for young Indigenous LGBTIQ+ peoples to imagine and determine their own futures.

\section{Discussion and Conclusions}

First Nations LGBTIQ+ people living in the Australian colonial settler state share a lot of common experiences with other First Nations people in the US, Canada and New Zealand. The most significant, would be the impact of colonisation, invasion, genocide, forced displacement and ethnocide upon First Nations people as a whole. This has set up heteropatriarchal, heteronormative value systems, processes and practices that exclude First Nations LGBTIQ+ people based on race and gender/sexuality diversity. However, although the articles in this issue reflect similar issues, we believe this issue stands alone by adding uniquely Aboriginal and/or Torres Strait Islander voices to this body of literature. This thematic issue also adds to the emerging body of research that highlights the unique, complex and place-based experiences of First Nations LGBTIQ+ people within Australia (see, for example, Bennett \& Gates, 2019; Clark, 2015, 2017; Costello, 2004; Day, 2020; Dudgeon et al., 2015; Dunn-Holland et al., 1994; Farrell, 2015; Hodge, 1993, 2015; Hope \& Haire, 2019; Kerry, 2014, 2017a, 2017b, 2018; Leonard et al., 2012; O'Sullivan, 2015, 2019; Riggs \& Toone, 2017; Ross, 2014; Sullivan, 2019; Willis, 2003).

Authors' approaches to examining the issues and meanings surrounding the lived experiences of First Nations LGBTIQ+ people in Australia were diverse. Various conceptual frameworks were used to interrogate data including Indigenous research methods, Indigenous Standpoint Theory, Critical Pedagogy, culturally appropriate social and emotional wellbeing, Borderland Theory and Intersectionality. All of these frameworks enriched the discussion and enable a more in-depth understanding of people's lives and experiences. Our authors also identified critical issues for First Nations LGBTIQ+ people and for future research agendas. Henningham (2021) argues that future research needs to focus on suicide and intergenerational trauma calling for more research into mental health to reduce suicide rates and improve wellbeing for Indigenous LGBTIQ+/bi+ youth. Phelan and Oxley (2021) conclude that, in order to improve youth justice approaches, criminal justice programmes need to base themselves on Aboriginal LGBTIQ+ youth voices, not Western constructs that currently skew approaches to criminal justice. This means a stronger engagement with Aboriginal and LGBTIQ+ communitycontrolled organisations, that can better represent Aboriginal LGBTIQ+ young people within the criminal justice system. To achieve the goal of an inclusive classroom, Rhodes and Byrne (2021) find that there is a need for a more systemic approach, with individual teachers having a pivotal role. However, they cannot do it alone and need appropriate education and training at university level, as well as support from state Education Departments and schools, which need to modify accepted practices and policies to create affirming and safe environments for Aboriginal LGBTIQ+ young people. Soldatic et al. (2021b) describe the numerous strategies young First Nations LGBTIQ+ people demonstrate when navigating and resisting neo-colonial attempts to erase identity, culture and wellbeing. Young people rely on networks of support from mothers, families and communities. Sullivan (2021) finds that existing literature does not capture the nuanced experiences of sex work, ignoring Aboriginal sex worker experiences and focusing too much on negativity and anxieties around cultural taboos. She calls on researchers to acknowledge the complex layers of identity for Aboriginal LGBTIQ+ sex workers and to speak back to "coloniocentric narratives" (Sullivan, 2021, p. 58).

Setting out a broader future research agenda is challenging given the fact that there is so very little published. The first important consideration would be that any research agenda be designed and led or coled by First Nations LGBTIQ+ people. We believe that, given the fact that First Nations cultures are placebased, this research agenda should also take a placebased approach and focus on the priorities and needs identified by First Nations LGBTIQ+ people themselves. Research also needs to balance strength-based with deficit approaches to give a more balanced understanding of not only disadvantage and exclusion but also strength and inclusion. As many of the articles discussed in this thematic issue, First Nations LGBTIQ+ people are overcoming feelings of isolation and disconnection and are creating opportunities to benefit their wellbeing and social inclusion and community connection. Finally, we need to understand the complexities of what we have generically termed First Nations LGBTIQ+ people. There is much diversity within First Nations LGBTIQ+ communities, gender and sexuality as well as Indigenous identities. As the collection of articles here suggest, a comprehensive, locally driven research agenda is required to better understand the ways in which different First Nation and LGBTIQ+ identities intersect and the impact of modern settler-colonialism on different genders, sexualities and Indigeneities. Looking at the existing literature in Australia, it is more developed in terms of research into cis-men, sistergirls, brotherboys and trans people, with a much smaller group of studies investigating lesbians, $\mathrm{Bi}+$ and queer cis-women. It is clear that a more in-depth understanding of the experiences of all these groups is needed, but with more of an emphasis on the latter.

\section{Acknowledgments}

We acknowledge the Aboriginal and/or Torres Strait Islander Peoples who are the traditional owners of the country upon which we all work. We recognise that sovereignty was never ceded and acknowledge and pay our respects to elders, past, present and future. 


\section{Conflict of Interests}

The authors declare no conflict of interests.

\section{References}

Aspin, C., \& Hutchings, J. (2007). Reclaiming the past to inform the future: Contemporary views of Maori sexuality. Culture, Health \& Sexuality, 9(4), 415-427.

Bayliss, T. (2015). Introduction: Looking into the mirror. In D. Hodge (Ed.), Colouring the rainbow: Blak, queer and trans perspectives. Life stories and essays by First Nations People of Australia (pp. 1-18). Mile End: Wakefield Press.

Bennett, B., \& Gates, T. (2019). Teaching cultural humility for social workers serving LGBTQI Aboriginal communities in Australia. Social Work Education, 38(5), 604-617.

Carlson, B. (2016). The politics of identity: Who counts as Aboriginal today? Canberra: Australian Institute of Aboriginal and Torres Strait Islander Studies.

Clark, M. (2015). Indigenous subjectivity in Australia: Are we Queer? Journal of Global Indigeneity, 1(1), 1-5.

Clark, M. (2017). Becoming-with and together: Indigenous transgender and transcultural practices. Artlink, 2(37), 76-81.

Costello, M. (2004). Sistergirls doing it for themselves. Aboriginal and Islander Health Worker Journal, 28(6). Retrieved from https://search.informit.org/doi/ 10.3316/ielapa.147926566032015

Day, M. (2020). Indigenist origins: Institutionalizing Indigenous queer and trans studies in Australia. Transgender Studies Quarterly, 7(3), 367-373.

Dudgeon, P., Bonson, D., Cox, A., Georgatos, G., \& Rouhani, L. (2015). The Aboriginal and Torres Strait Islander suicide prevention evaluation project (ATSISPEP): Sexuality and gender diverse populations (lesbian, gay, bisexual, transsexual, queer and intersex-LGBTQI): Roundtable report. Canberra: The Healing Foundation.

Dunn-Holland, W., Fletcher, M., Hodge, D., Lee, G., Milera, E. J., Saunders, R., \& Wafer, J. (1994). Peopling the empty mirror. The prospects of lesbian and gay Aboriginal history. In R. Aldrich (Ed.), Gay perspectives II: More essays in Australian gay culture (pp. 1-62). Sydney: University of Sydney.

Farrell, A. (2015). Can you see me? Queer margins in Aboriginal communities. Journal of Global Indigeneity, 1(3), 1-4.

Henningham, M. (2021). Blak, bit and borderlands: An autoethnography on multiplicities of Indigenous queer identities using borderland theory. Social Inclusion, 9(2), 7-17.

Hodge, D. (1993). Did you meet any Malagas? A homosexual history of Australia's tropical capital. Nightcliff: Little Gem Publications.

Hodge, D. (2015). Colouring the rainbow: Black queer and trans perspectives. Life stories and essays by
First Nations people of Australia. Mile End: Wakefield Press.

Hope, A., \& Haire, B. (2019). "No-one's driving this bus"Qualitative analysis of PrEP health promotion for Aboriginal and Torres Strait Islander gay and bisexual men. Australian and New Zealand Journal of Public Health, 43(1), 18-23.

Kerry, S. (2014). Sistergirls/brotherboys: The status of Indigenous transgender Australians. International Journal of Transgenderism, 15, 173-186.

Kerry, S. (2017a). Trans dilemmas: Living in Australia's remote areas and in Aboriginal communities. Oxon: Routledge.

Kerry, S. (2017b). Transgender people in Australia's Northern Territory. The International Journal of Transgenderism, 18(2), 129-139.

Kerry, S. (2018). Payback: The custom of assault and rape of sistergirls and brotherboys, Australia's trans and sex/gender diverse first peoples. Violence and Gender, 5(1), 37-41.

Leonard, W., Pitts, M., Mitchell, A., Lyons, A., Smith, A., Patel, S., \& Barrat, A. (2012). Private lives 2: The second national survey on the health and wellbeing of GLBT Australians. Melbourne: Australian Research Centre in Sex, Health \& Society, La Trobe University.

O'Sullivan, S. (2015). Presentation: Sandy O'Sullivan. Journal of Global Indigeneity, 1(1).

O'Sullivan, S. (2019). Practice futures for Indigenous agency. In J. Higgs, S. Cork, \& D. Horsfall (Eds.), Challenging future practice possibilities (pp. 91-100). Boston: Brill Sense.

O'Sullivan, S. (2021). Saving lives: Mapping the power of LGBTIQ+ First Nations creative artists. Social Inclusion, 9(2), 61-64.

Phelan, P., \& Oxley, R. (2021). Understanding the social and emotional wellbeing of aboriginal LGBTIQ(SB)+ youth in Victoria's youth detention. Social Inclusion, 9(2), 18-29.

Rhodes, D., \& Byrne, M. (2021). Embedding Aboriginal and Torres Strait Islander LGBTIQ+ issues in primary initial teacher education programs. Social Inclusion, 9(2), 30-41.

Riggs, D., \& Toone, K. (2017). Indigenous sistergirls' experiences of family and community. Australian Social Work, 2(70), 229-240. https://doi.org/ 10.1080/0312407X.2016.1165267

Ross, S. (2014). Homosexuality and Aboriginal culture: Archer, a lore unto themselves. Archer Magazine, 2. Retrieved from http://archermagazine.com.au/ 2014/10/homosexualityand-aboriginal-culture-alore-unto-themselves

Soldatic, K., Briskman, L., Trewlynn, W., Leha, J., \& Spurway, K. (2021a). Social and emotional wellbeing of Indigenous gender and sexuality diverse youth: Mapping the evidence. Culture, Health \& Sexuality. Advance online publication. https://doi.org/ 10.1080/13691058.2021.1873421

Soldatic, K., Briskman, L., Trewlynn, W., Leha, J., \& Spur- 
way, K. (2021b). Social exclusion/inclusion and australian First Nations LGBTIQ+ young people's wellbeing. Social Inclusion, 9(2), 42-51.

Sullivan, C. (2020). Majesty in the city: Experiences of an Aboriginal transgender sex worker in Sydney, Australia. Gender, Place \& Culture, 25(12), 1681-1702. https://doi.org/https://doi.org/10.1080/0966369X. 2018.1553853

Sullivan, C. (2021). 'Hot, young, buff': An Indigenous Australian gay male view of sex work. Social Inclusion,
9(2), 52-60.

Tuhiwai Smith, L. (2013). Decolonizing methodologies: Research and Indigenous peoples. New York, NY: Palgrave. https://doi.org/10.1080/09614524.2013. 790946

Willis, J. (2003). Heteronormativity and the deflection of male same-sex attraction among the Pitjantjatjara people of Australia's Western Desert. Culture, Health and Sexuality, 5(2), 137-151.

\section{About the Authors}
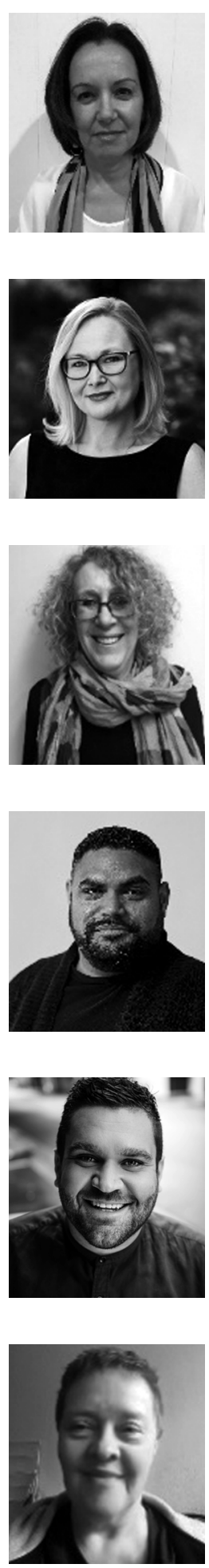

Karen Soldatic is Associate Professor at the School of Social Sciences and Psychology and Institute Fellow in the Institute for Culture and Society both at Western Sydney University. Karen's research engages with critical questions of identity, race, ethnicity, disability and sexuality under settler colonial regimes of power.

Corrinne Sullivan is an Aboriginal scholar from the Wiradjuri Nation in Central-West New South Wales. She is a Senior Lecturer in Geography at Western Sydney University, Sydney, Australia, and a PhD candidate at Macquarie University, Sydney, Australia. Her research interests are multi-disciplinary and focus broadly on experiences and effects of body and Identity in relation to Aboriginal and Torres Strait Islander peoples. Corrinne's knowledges stem from the disciplines of Indigenous Studies and Human Geography, she utilises both to understand the ways in which Aboriginal and Torres Strait Islander peoples are affected by their experiences of space and place.

Linda Briskman holds the Margaret Whitlam Chair of Social Work at Western Sydney University. Areas of research and activism include asylum seeker rights, Indigenous rights and challenging racism. She publishes widely in each area. Her most recent book is the co-edited Indigenous Health Ethics: An Appeal To Human Rights (World Scientific, 2021).

John Leha is BlaQ's founding Director and Chair of BlaQ Aboriginal Corporation. John has worked extensively in the Indigenous sector across all levels of government and community controlled organisations. John is a proud Birra Gubba, Wakka Wakka and Tongan man born and raised on Gadigal land, Sydney.

William Trewlynn is a founding Director and appointed CEO of BlaQ Aboriginal Corporation. He is a proud Aboriginal man with traditional ties to the Nucoorilma people of Tingha and Dunghutti people of Woolbrook NSW. As a Queer Aboriginal man, William has experienced firsthand the hardships the community face. 